\title{
Significant associations of PAl-1 genetic polymorphisms with osteonecrosis of the femoral head
}

Hye- Ok Kim ${ }^{1,2}$, Chang- Hoon Cho ${ }^{1,2}$, Yoon- Je Cho ${ }^{3}$, Seong- Ho Cho ${ }^{1,4}$, Kyung- Sik Yoon ${ }^{1,2}$ and Kang- $\|$ Kim $^{3^{*}}$

\begin{abstract}
Background: The pathogenesis of osteonecrosis of the femoral head (ONFH) has been implicated in hypofibrinolysis and blood supply interruption. Previous studies have demonstrated that decreased fibrinolytic activity due to elevated plasminogen activator inhibitor-1 (PAI-1) levels correlates with ONFH pathogenesis. The -675 4G/5G single nucleotide polymorphism (SNP rs1799889) in the PAl-1 gene promoter is associated with PAl-1 plasma level. We investigated whether rs1799889 and two other SNPs of the PAl-1 gene (rs2227631, -844 G/A in the promoter; rs11178, +10700 C/T in the $3^{\prime} \mathrm{UTR}$ ) are associated with increased ONFH risk.

Methods: Three SNPs in PAl-1 were genotyped in 206 ONFH patients and 251 control subjects, using direct sequencing and a $\operatorname{TaqMan}^{\circledR} 5^{\prime}$ allelic discrimination assay. We performed association analysis for genotyped SNPS and haplotypes with ONFH.

Results: The 4G allele of rs1799889, A allele of rs2227631, and C allele of rs11178 were significantly associated with increased ONFH risk ( $p=0.03, p=0.003$, and $p=0.002$, respectively). When we divided the population according to gender, an association between the three SNPs and increased risk of ONFH was found only in men. In another subgroup analysis based on the etiology of ONFH, rs2227631 (A allele) and rs11178 (C allele) in the idiopathic subgroup ( $p=0.007$ and $p=0.021$ ) and rs1799889 (4G allele) and rs11178 (C allele) in the alcohol-induced subgroup ( $p=0.042$ and $p=0.015$ ) were associated with increased risk of ONFH. In addition, a certain haplotype (A-4G-C) of PAl-1 was also significantly associated with ONFH $(p<0.001)$.
\end{abstract}

Conclusion: Our findings demonstrated that three SNPs (rs1799889, rs2227631, and rs11178) of the PAl-1 gene were associated with ONFH risk. This study also suggests that PAl-1 SNPs may play an important role in ONFH.

\section{Background}

Osteonecrosis of the femoral head (ONFH) is a devastating bone disease in which patients experience progressive collapse of the femoral head caused by a disturbance in the supply of blood and anomalies in the fibrinolytic system $[1,2]$. An increased tendency for intravascular coagulation is proposed as the pathogenetic mechanism responsible for interruption of the osseous blood supply and ONFH, and a significantly higher prevalence of coagulation abnormalities is reported in patients with ONFH $[1,3]$. Recent studies have suggested that genetic polymorphisms in factor $\mathrm{V}$, prothrombin,

\footnotetext{
* Correspondence: drkim@khu.ac.kr

${ }^{3}$ Department of Orthopaedic Surgery, Kyung Hee University Hospital at

Gangdong, School of Medicine, Kyung Hee University, Seoul, 134-727, Korea Full list of author information is available at the end of the article
}

methylenetetrahydrofolate reductase (MTHFR), and plasminogen activator inhibitor-1 (PAI-1) genes leading to intravascular coagulation disorders may be related to ONFH [4-6].

PAI-1 is a critical factor that regulates coagulation and fibrinolytic systems. Reduced plasma fibrinolytic activity, mainly attributable to increased levels of PAI-1, is associated with ONFH development $[7,8]$. Previously, PAI-1 levels were reported to be regulated by a common transcription-altering insertion/deletion single nucleotide polymorphism (SNP; rs1799889) of four or five guanine (4G/ 5G) nucleotides that is 675 bp upstream of the transcription start site. Homozygous or heterozygous carriage of the 4G allele is associated with higher PAI-1 levels [9]. In myocardiac infarction, subjects who are homozygous for the $4 \mathrm{G}$ allele ( $4 \mathrm{G} / 4 \mathrm{G}$ genotype) have plasma PAI-1

C Biomed Central

(C) 2011 Kim et al; licensee BioMed Central Ltd. This is an Open Access article distributed under the terms of the Creative Commons Attribution License (http://creativecommons.org/licenses/by/2.0), which permits unrestricted use, distribution, and reproduction in any medium, provided the original work is properly cited. 
concentrations that are approximately $25 \%$ higher than those of subjects who are homozygous for the $5 \mathrm{G}$ allele (5G/5G genotype) [10]. Glueck et al. first reported that the genotype frequency of $4 \mathrm{G} / 4 \mathrm{G}$ was $41 \%$ in ONFH patients and $20 \%$ in healthy control subjects [8]. Moreover, Ferrari et al. reported a significant increase in the frequency of the 4G/4G genotype in renal transplant patients with ONFH compared to that of controls (60.3\% vs. 20.6\%) [7]. However, Asano et al. suggested that plasma PAI-1 levels are highest in ONFH patients with the 4G/4G genotype, but that the incidence of ONFH is not related to genotype [11]. To better understand the genetic influences of PAI-1 on ONFH, we selected SNPs in the promoter and 3'UTR that are known to be involved in the regulation of gene expression. To determine whether PAI-1 SNPs, including 4G/5G, are associated with susceptibility to ONFH, genotype and allele frequencies were analyzed. We also investigated whether pathological etiology (idiopathic, alcoholor steroid-induced) is involved in the association of SNPs and ONFH.

\section{Methods}

\section{Patients and controls}

A total of 206 (159 men, 47 women; mean age $44.2 \pm$ 11.6) patients with non-traumatic ONFH who had total hip arthroplasty at Kyunghee University Hospital (Seoul, Korea) were consecutively enrolled in this study. The diagnosis of symptomatic ONFH was based on anteroposterior and lateral pelvic radiography and magnetic resonance images. Patients were subgrouped according to etiological factors into idiopathic (98 cases), steroidinduced (72 cases), and alcohol-induced (36 cases) ONFH. Patients with a demonstrable history of direct trauma or with possible combined causes were excluded. Steroid-induced ONFH was defined by a history of taking prednisolone $1800 \mathrm{mg}$ or the equivalent over 4 weeks with nephritic syndrome, and organ transplantation [12]; and alcohol-induced ONFH was diagnosed based on the consumption of more than $400 \mathrm{ml}$ of alcohol per week [13]. Patient characteristics are summarized in Table 1.

Controls were recruited from subjects attending routine medical checkups at our institution who had no coagulation-related disorder or other chronic disease, such as diabetes or cardiovascular disease (CHD). Control subjects were matched with patients with regard to gender and age (193 men, 58 women; mean age $47.8 \pm$ 12.6). This study was approved by the Institutional Review Board at our hospital, and informed consent was obtained from all patients.

\section{Polymerase chain reaction and genotyping}

Genomic DNA was isolated from peripheral blood leukocytes using an AxyPrep Blood Genomic DNA Miniprep kit (Axygen Biosciences, Union, CA, USA). The $\sim 1.0 \mathrm{~kb}$ promoter region of the PAI-1 gene was partially amplified using PCR and analyzed via direct sequencing. All PCR reactions were in a $20 \mu \mathrm{l}$ volume containing 1.5 $\mathrm{mmol} / \mathrm{L} \mathrm{MgCl}_{2}, 40 \mathrm{mmol} / \mathrm{L} \mathrm{KCl}, 10 \mathrm{mmol} / \mathrm{L}$ Tris- $\mathrm{HCl}$ (pH 9.0), $250 \mu \mathrm{mol} / \mathrm{L}$ dNTP, 1 U Taq DNA polymerase (Bioneer, Daejeon, Korea) and 50 ng genomic DNA in distilled water. The forward primer 5' GTG CTT GAA TCA TCC CGA AAC 3' and reverse primer 5' TCT GGA CCA CCT CCA GGA AA 3' were used for amplification. The conditions for the PCR reaction were denaturation at $95^{\circ} \mathrm{C}$ for $10 \mathrm{~min}$, followed by 35 cycles of denaturation at $95^{\circ} \mathrm{C}$ for $30 \mathrm{sec}$, annealing at $58^{\circ} \mathrm{C}$ for $30 \mathrm{sec}$, and extension at $72^{\circ} \mathrm{C}$ for $30 \mathrm{sec}$, followed by a final extension at $72^{\circ} \mathrm{C}$ for $10 \mathrm{~min}$. PCR products purified with 95\% ethyl alcohol were used as template DNA for cycle sequencing. The PCR for sequencing was performed using a Big Dye Terminator (ver 3.1) cycle sequencer and analyzed using an ABI Prism ${ }^{\circledR} 3730$ Automated DNA sequencer (Applied Biosystems, Foster City, CA, USA).

The SNP of the PAI-1 3'UTR (rs11178) was analyzed with primers and probes for TaqMan ${ }^{\circledR}$ SNP genotyping assays. Primer Express (Applied Biosystems, Foster City, CA, USA) was used to design both the PCR primers and the MGB TaqMan ${ }^{\circledR}$ probes. One allelic probe was labeled with 6-carboxyl-fluorescent $(\text { FAM })^{\mathrm{TM}}$ dye and the other was labeled with fluorescent VIC ${ }^{\circledR}$ dye. PCRs were carried out in TaqMan ${ }^{\circledR}$ Universal Master mix without UNG (Uracil-N-Glycosylase; Applied Biosystems), containing PCR primer concentrations of $900 \mathrm{nM}$ and TaqMan ${ }^{\circledR}$ MGB-probe concentrations of $200 \mathrm{nM}$. Reactions occurred in a 96-well plate with a total reaction volumes of $10 \mu \mathrm{l}$ using $20 \mathrm{ng}$ of genomic DNA.

Table 1 Characteristics of ONFH patients and controls

\begin{tabular}{|c|c|c|c|c|c|}
\hline & \multirow{2}{*}{$\begin{array}{l}\text { Controls } \\
(n=251)\end{array}$} & \multicolumn{4}{|c|}{ Patients } \\
\hline & & $\begin{array}{l}\text { Total } \\
(n=206)\end{array}$ & $\begin{array}{l}\text { Idiopathic } \\
(n=98)\end{array}$ & $\begin{array}{l}\text { Alcohol-induced } \\
(n=72)\end{array}$ & $\begin{array}{l}\text { Steroid-induced } \\
(n=36)\end{array}$ \\
\hline Age $\left(\right.$ year) ${ }^{a}$ & $47.8 \pm 12.6$ & $44.2 \pm 11.6$ & $44.9 \pm 12.3$ & $45.7 \pm 10.2$ & $39.3 \pm 10.9$ \\
\hline $\operatorname{Sex}(M / F)$ & $193 / 58$ & $159 / 47$ & $78 / 20$ & $62 / 10$ & 19/17 \\
\hline BMI $\left(\mathrm{kg} / \mathrm{m}^{2}\right)^{\mathrm{a}}$ & $23.6 \pm 3.5$ & $24.2 \pm 3.3$ & $24.4 \pm 3.6$ & $24.1 \pm 2.9$ & $24.4 \pm 3.3$ \\
\hline
\end{tabular}


Plates were placed in a thermal cycler (7300 SDS 1.2.2, Applied Biosystems, Foster City, CA, USA) and heated at $50^{\circ} \mathrm{C}$ for $2 \mathrm{~min}$ and $95^{\circ} \mathrm{C}$ for $10 \mathrm{~min}$, followed by 40 cycles at $92^{\circ} \mathrm{C}$ for $15 \mathrm{sec}$ and $60^{\circ} \mathrm{C}$ for $1 \mathrm{~min}$, with postreading at $60^{\circ} \mathrm{C}$ for $1 \mathrm{~min}$. Fluorescence data files were analyzed using automated allele-calling software (SDS 2.1, Applied Biosystems, Foster City, CA, USA). Genotyping quality control was performed in $10 \%$ of samples via duplicate checking (rate of concordance in duplicates > 99\%).

\section{Statistical analysis}

We tested significant deviations in genotype frequency from Hardy-Weinberg equilibrium (HWE) at each polymorphic variant using the $\chi^{2}$ test. Odds ratios (ORs) and $95 \%$ confidence intervals (CIs) were used to estimate the relative risks of ONFH patients associated with the presence of different PAI-1 genotypes. We employed a widely used measure of linkage disequilibrium (LD) between all pairs of biallelic loci, D', and $r^{2}$. Haplotype structures and their frequencies were estimated from genotyped data using Haploview http://www.broad.mit. $\mathrm{edu} / \mathrm{mpg} /$ haploview based on the expectation maximization (EM) algorithm. The $\chi^{2}$ test was used to compare the frequencies of discrete variables between ONFH patients and controls. All statistical analyses were performed using SPSS for Windows version 16.0 and pvalues less than 0.05 were regarded as significant. All statistical tests were two-sided.

\section{Results}

To identify if PAI-1 SNPs were involved in susceptibility to ONFH, three SNPs in the promoter and 3'UTR were selected based on a minor allele frequency (MAF) > 0.05 and Hardy-Weinberg equilibrium (HWE) > 0.05 using a public database http://www.ncbi.nlm.nih.gov/ SNP/. Two SNPs (rs2227631, -844 G/A; rs1799889, -675 $4 \mathrm{G} / 5 \mathrm{G}$ ) in the promoter region and one ( $\mathrm{rs} 11178$, $+10700 \mathrm{C} / \mathrm{T}$ ) in the 3'UTR of the PAI-1 gene were genotyped in 206 ONFH and 251 control subjects (Table 2).

The $\mathrm{p}$ value of each polymorphism was determined for comparison between ONFH patients and controls. The rs2227631, rs1799889, and rs11178 genotypes and/or allele frequencies of the PAI-1 gene were significantly associated with ONFH risk ( $\mathrm{p}=0.002-0.03)$. These results suggest that the minor alleles of rs2227631 (A), rs1799889 (4G), and rs11178 (C) in the PAI-1 gene contribute to an increase in ONFH risk (Table 3).

Further analysis based on pathological etiology (idiopathic, alcohol- or steroid-induced) showed that the allele frequencies of PAI-1 (rs2227631 and rs11178) between idiopathic ONFH patients and controls were significantly associated ( $\mathrm{p}=0.007$ and 0.021 ). In addition, the allele frequencies of rs1799889 and rs11178 were significantly associated with the alcohol-induced ONFH subgroup ( $\mathrm{p}=0.042$ and 0.015 , respectively). These results suggest that the PAI-1 SNPs were important risk factors in idiopathic (rs2227631, rs11178) and alcohol-induced (rs1799889, rs11178) ONFH (Table 4). In addition, the association of PAI-1 polymorphisms was further analyzed in the ONFH subgroup stratified according to gender. Interestingly, the genotype frequencies of rs2227631, rs1799889, and rs11178 were significantly associated with ONFH in men but not in women (Table 5). These results suggest that the PAI-1 SNPs might be important genetic factors in ONFH susceptibility in men.

We analyzed linkage LDs among the PAI-1 SNPs and did not observe complete LD for the PAI-1 gene. LD between SNPs was estimated by calculating the D' values (Table 6). We also calculated the haplotype frequencies of rs2227631, rs1799889, and rs11178 in ONFH patients and controls. The distribution of haplotype A-4G-C was significantly different between the ONFH patients and controls ( $\mathrm{p}<0.001$ ) (Table 7 ). These results suggest that these SNPs should be further analyzed in future studies regarding PAI-1 functions and ONFH.

\section{Discussion}

We determined the contributions of PAI-1 gene SNPs to ONFH. We identified for the first time a significant association between SNPs of the PAI-1 gene (rs2227631; -844 G/A, rs1799889; -675 4G/5G, rs11178; +10700 C/ $\mathrm{T})$ and $\mathrm{ONFH}$ in Koreans. The A, 4G, and $\mathrm{C}$ alleles considerably increased disease risk (Table 3).

Table 2 Frequencies of PAl-1 polymorphisms $(n=457)$

\begin{tabular}{|c|c|c|c|c|c|c|c|}
\hline Position $^{a}$ & Location & & Genotype & & & $\mathrm{MAF}^{\mathrm{c}}$ & Heterozygosity \\
\hline g. $-844 \mathrm{G} / \mathrm{A}$ & promoter & GG & GA & $\mathrm{AA}$ & $\mathrm{N}$ & 0.387 & 0.425 \\
\hline$(\mathrm{rs} 2227631)$ & & 183 & 194 & 80 & 457 & & \\
\hline g. $-6754 G / 5 G$ & promoter & $4 G 4 G$ & $4 \mathrm{G} 5 \mathrm{G}$ & $5 G 5 G$ & $\mathrm{~N}$ & 0.410 & 0.492 \\
\hline (rs1799889) & & 157 & 225 & 75 & 457 & & \\
\hline g.10700 & $3^{\prime}-U_{T R}^{b}$ & $\mathrm{CC}$ & $\mathrm{CT}$ & $\pi$ & $N$ & 0.500 & 0.457 \\
\hline (rs11178) & & 124 & 209 & 124 & 457 & & \\
\hline
\end{tabular}

${ }^{a}$ rs No. was shown if present in the dbSNP database; ${ }^{b}{ }^{\prime}$-untranslated region; ${ }^{c}$ frequencies of minor alleles 
Table 3 Genotypes and allelic frequencies of PAl-1 gene polymorphisms between ONFH patients $(n=206)$ and controls $(n=251)$

\begin{tabular}{|c|c|c|c|c|c|}
\hline Position & Genotype/Allele & Controls, n (\%) & Patients, n (\%) & OR (95\% Cl) & $p$ \\
\hline g. $-844 \mathrm{G} / \mathrm{A}$ & GG & $116(46.2)$ & $67(32.5)$ & $1^{*}$ & 0.011 \\
\hline \multirow[t]{4}{*}{ (rs2227631) } & GA & 97(38.6) & 97(47.1) & $1.73(1.15-2.61)$ & \\
\hline & $\mathrm{AA}$ & $38(15.1)$ & $42(20.4)$ & $1.91(1.12-3.26)$ & \\
\hline & G & $329(65.5)$ & $231(56.1)$ & $1^{*}$ & 0.003 \\
\hline & A & $173(34.5)$ & 181(43.9) & 1.49(1.14-1.95) & \\
\hline g. $-6754 \mathrm{G} / 5 \mathrm{G}$ & $5 G 5 G$ & 46(18.3) & $29(14.1)$ & $1^{*}$ & 0.073 \\
\hline \multirow[t]{4}{*}{ (rs1799889) } & $4 \mathrm{G} 5 \mathrm{G}$ & 130(51.8) & $95(46.1)$ & $1.16(0.68-1.98)$ & \\
\hline & $4 \mathrm{G} 4 \mathrm{G}$ & 75(29.9) & 82(39.8) & $1.73(0.99-3.04)$ & \\
\hline & $5 G$ & $222(44.2)$ & 153(37.1) & $1^{*}$ & 0.030 \\
\hline & $4 \mathrm{G}$ & 280(55.8) & 259(62.9) & $1.34(1.03-1.75)$ & \\
\hline g. $10700 \mathrm{C} / \mathrm{T}$ & $\pi$ & 79(31.5) & $45(21.8)$ & $1^{*}$ & 0.013 \\
\hline \multirow[t]{4}{*}{ (rs11178) } & CT & 116(46.2) & 93(45.1) & $1.41(0.89-2.22)$ & \\
\hline & CC & $56(22.3)$ & $68(33.0)$ & $2.13(1.28-3.55)$ & \\
\hline & $\mathrm{T}$ & 274(54.6) & 183(44.4) & $1^{*}$ & 0.002 \\
\hline & C & $228(45.4)$ & 229(55.6) & $1.50(1.16-1.95)$ & \\
\hline
\end{tabular}

*reference category (odds ratio, 1.0)

PAI-1 is a fast-acting inhibitor of fibrinolysis, and increased plasma levels are associated with increased incidence of thrombophilia [14] and osteonecrosis $[8,11,15,16]$. High levels of PAI-1, induced by $-6754 \mathrm{G} /$ 5 G SN in the PAI-1 promoter, lead to suppression of fibrinolysis through inhibition of plasminogen activator and promotion of thrombosis. The resulting increase in intraosseous venous pressure which restricts flow to the femoral head may culminate in osteonecrosis $[8,16]$. The PAI-1 gene is reported to be polymorphic, especially in rs1799889 (-675 4G/5G) of the promoter region. The possible association between rs1799889 and osteonecrosis risk has been studied, leading to controversial results. Glueck et al. and Ferrari et al. reported that the 4G allele is a major predisposing factor in ONFH patients $[7,8]$, but the findings of Asano et al. were contradictory to that conclusion [11]. Glueck et al. showed that, in Americans, twice as many patients as healthy control subjects ( $41 \%$ vs. 20\%) were homozygous for $4 \mathrm{G} / 4 \mathrm{G}$, and $19 \%$ of patients and $36 \%$ of the control subjects had the 5G/5G genotype ( $p=0.001)$ [7]. Furthermore, Ferrari $\mathrm{P}$. et al. observed that in 228 glucocorticoid-treated renal transplant patient in Switzerland, the prevalence of ONFH according to genotype was $1.8 \%$ for $5 \mathrm{G} / 5 \mathrm{G}, 7.7 \%$ for $4 \mathrm{G} / 5 \mathrm{G}$, and $30.3 \%$ for $4 \mathrm{G} / 4 \mathrm{G}$ (p < 0.001 vs. $4 \mathrm{G} / 5 \mathrm{G}$ and $5 \mathrm{G} / 5 \mathrm{G}$ ); the prevalence of ONFH according to genotype in subjects with persistent hyperparathyroidism was $4.2 \%$ for $5 \mathrm{G} / 5 \mathrm{G}, 15.2 \%$ for $4 \mathrm{G} / 5 \mathrm{G}$, and $55.5 \%$ for

Table 4 Genotypes and allelic frequencies of PAI-1 gene polymorphisms between ONFH subtype patients $(\mathrm{n}=206$ ) and controls $(\mathbf{n}=\mathbf{2 5 1})$

\begin{tabular}{|c|c|c|c|c|c|c|c|c|}
\hline \multirow[b]{2}{*}{ Position } & \multirow[b]{2}{*}{ Genotype } & \multirow[b]{2}{*}{ Controls } & \multicolumn{3}{|c|}{ Patients } & \multicolumn{3}{|c|}{$p$} \\
\hline & & & $\mathrm{Idi}^{\mathrm{a}}$ & $\mathrm{Alc}^{\mathrm{b}}$ & Ste ${ }^{c}$ & vs Idi & Alc & Ste \\
\hline g. $-844 G / A$ & G & $329(65.5)$ & $107(54.6)$ & 83(57.6) & $41(56.9)$ & 0.007 & 0.082 & 0.154 \\
\hline \multirow[t]{3}{*}{ (rs2227631) } & A & $173(34.5)$ & $89(45.4)$ & $61(42.4)$ & $31(43.1)$ & & & \\
\hline & $\mathrm{GG}+\mathrm{GA}$ & 213(84.9) & $75(76.5)$ & $61(84.7)$ & $28(77.8)$ & 0.066 & 0.977 & 0.279 \\
\hline & AA & $38(15.1)$ & $23(23.5)$ & $11(15.3)$ & $8(22.2)$ & & & \\
\hline g. $-6754 \mathrm{G} / 5 \mathrm{G}$ & $5 G$ & $222(44.2)$ & $76(38.8)$ & $50(34.7)$ & $27(37.5)$ & 0.191 & 0.042 & 0.282 \\
\hline \multirow[t]{3}{*}{ (rs1799889) } & $4 \mathrm{G}$ & $280(55.8)$ & $120(61.2)$ & $94(65.3)$ & $45(62.5)$ & & & \\
\hline & $4 G 5 G+5 G 5 G$ & 176(70.1) & $61(62.2)$ & $41(56.9)$ & $22(61.1)$ & 0.157 & 0.036 & 0.274 \\
\hline & $4 \mathrm{G} 4 \mathrm{G}$ & $75(29.9)$ & $37(37.8)$ & $31(43.1)$ & 14(38.9) & & & \\
\hline g.10700C/T & $\mathrm{T}$ & $274(54.6)$ & $88(44.9)$ & $62(43.1)$ & $33(45.8)$ & 0.021 & 0.015 & 0.164 \\
\hline \multirow[t]{3}{*}{ (rs11178) } & C & $228(45.4)$ & $108(55.1)$ & $82(56.9)$ & $39(54.2)$ & & & \\
\hline & $\mathrm{TT}+\mathrm{CT}$ & 195(77.7) & $66(67.3)$ & $47(65.3)$ & $25(69.4)$ & 0.046 & 0.032 & 0.274 \\
\hline & CC & $56(22.3)$ & $32(32.7)$ & $25(34.7)$ & 11(30.6) & & & \\
\hline
\end{tabular}


Table 5 Genotype frequencies of PAI-1 gene polymorphisms between ONFH patients and controls in men and women

\begin{tabular}{|c|c|c|c|c|c|c|c|}
\hline \multirow[b]{2}{*}{ Position } & \multirow[b]{2}{*}{ Genotype } & \multicolumn{3}{|c|}{ Men } & \multicolumn{3}{|c|}{ Women } \\
\hline & & Controls & Patients & $p$ & Controls & Patients & $p$ \\
\hline g. $-844 \mathrm{G} / \mathrm{A}$ & GG & $92(47.7)$ & $53(33.3)$ & 0.025 & $24(41.4)$ & $14(29.8)$ & 0.386 \\
\hline \multirow[t]{2}{*}{ (rs2227631) } & GA & $71(36.8)$ & $74(46.5)$ & & $26(44.8)$ & 23(48.9) & \\
\hline & $\mathrm{AA}$ & $30(15.5)$ & $32(20.1)$ & & $8(13.8)$ & $10(21.3)$ & \\
\hline g. $-6754 \mathrm{G} / 5 \mathrm{G}$ & $5 G 5 G$ & $37(19.2)$ & $21(13.2)$ & 0.030 & $9(15.5)$ & $8(17.0)$ & 0.976 \\
\hline \multirow[t]{2}{*}{ (rs1799889) } & $4 \mathrm{G} 5 \mathrm{G}$ & 102(52.8) & 73(45.9) & & 28(48.8) & $22(46.8)$ & \\
\hline & $4 \mathrm{G} 4 \mathrm{G}$ & $54(28.0)$ & 65(40.9) & & $21(36.2)$ & $17(36.2)$ & \\
\hline g.10700C/T & $\pi$ & $62(32.1)$ & $33(20.8)$ & 0.003 & $17(29.3)$ & $12(25.5)$ & 0.718 \\
\hline \multirow[t]{2}{*}{ (rs11178) } & $C T$ & $91(47.2)$ & $69(43.4)$ & & $25(43.1)$ & $24(51.1)$ & \\
\hline & CC & $40(20.7)$ & $57(35.8)$ & & $16(27.6)$ & $11(23.4)$ & \\
\hline
\end{tabular}

4G/4G (p $<0.003$ vs. $4 \mathrm{G} / 5 \mathrm{G}$ and $\mathrm{p}<0.001$ vs. 5G/5G) [8]. Asano et al. studied 31 Japanese patients with postrenal transplant ONFH and found four patients with 5G/5G, 11 with 4G/5G, and 16 with 4G/4G. However, analysis revealed no significant differences in the incidence of ONFH among these patients $(\mathrm{p}=0.49)$ [11].

In addition to rs1799889, another SNP in the promoter region of PAI-gene, rs2227631 (-844 G/A), is potentially implicated in PAI-1 gene regulation. To date, a significant association has been reported between this SNP and coronary heart disease (CHD) in nonsmokers, with patients having a higher frequency of rs2227631 A allele. In addition to rs2227631 and rs1799889, rs11178 $(+10700 \mathrm{C} / \mathrm{T})$ also significantly associates with increased $\mathrm{CHD}$ risk in nonsmokers. The correlation between rs11178 and CHD in nonsmokers might be attributable to strong linkage LD of this SNP with rs2227631 and rs1799889 [17]. For ONFH, the results of our study confirmed an association between rs1799889 and disease risk in a Korean population. Moreover, for the first time, we showed that rs2227631 and rs11178 are essential SNPs involved in the regulation of PAI-1 gene expression in ONFH (Table 3).

Several transcription factor binding sites for PAI-1 are found in the 5' and 3' UTR regions, and the transcriptional regulation of the gene is extremely complex [18]. Several studies have shown that SNPs within the 5'UTR lead to differences in PAI-1 expression between individuals, and this could influence the etiology of a variety of pathological conditions with which PAI-1 is associated such as cancer, rheumatoid arthritis and stroke

Table 6 LD coefficients (|D' |) and $r^{2}$ among polymorphisms in the PAI-1 gene

\begin{tabular}{ccccc}
\hline & & & $\left|\mathbf{D}^{\prime}\right|$ & \\
& SNPs & rs2227631 & rs1799889 & rs11178 \\
\hline$r^{2}$ & rs2227631 & - & 0.932 & 0.786 \\
& rs1799889 & 0.382 & - & 0.786 \\
& rs11178 & 0.391 & 0.43 & - \\
\hline
\end{tabular}

[19-21]. We classified ONFH into two or three major subgroups based on etiology and gender: idiopathic, alcohol-induced, steroid-induced groups, and men and women. We found that the risk effects of rs2227631 and rs11178 in the idiopathic subgroup, rs1799889 and rs11178 in the alcohol-induced subgroup, and all three SNPs in men were significantly associated with ONFH. However, no association was seen in the steroid-induced group or in women. Glucocorticoid has been reported to increase PAI-1 activity and is a potential risk factor for ONFH development $[7,22]$. However, we had limited data on SNPs of PAI-1 in steroid-induced ONFH. The incidence of ONFH is relatively low and gender-biased. We examined 206 cases, of which 159 (77\%) were men. Moreover, epidemiologic analysis showed that the incidence of steroid-induced ONFH in overall ONFH was low (17.5\%). In Korean studies, the proportion of steroid-induced ONFH was previously shown to be small (range, $12.6 \%$ to $15.4 \%$ ) [23,24]. We found that, in Koreans, steroid-induced ONFH is more rare than idiopathic or alcohol-induced ONFH. Thus, we found no significant association between PAI-1 SNPs and steroidinduced ONFH because of the small sample size. In addition, differences according to subgroup could not be clearly distinguished. Therefore, the association analysis strategy of subgrouping according to gender or etiology has limitations. However, the results of the steroidinduced group showed a similar tendency as those of the other groups, demonstrating that patients more often have risk alleles (A, 4G, and C) than do control subjects, although this finding was not significant (Table 4 and 5). Thus, we suggest that PAI-1 SNPs are involved in ONFH risk in Korean patients. To firmly establish the relationship between the PAI-1 SNPs and steroidinduced $\mathrm{ONFH}$, further study with larger sample sizes is required.

The pathophysiology of ONFH is not well known, although a number of polymorphisms in candidate genes (HIF-1, VEGF, eNOS, IL23R, SREBP-2, ANXA6) were recently identified in an attempt to determine the 
Table 7 Haplotype frequencies of PAI-1 gene polymorphisms between ONFH patients $(n=206)$ and controls $(n=251)$

\begin{tabular}{|c|c|c|c|c|c|c|c|}
\hline & \multicolumn{3}{|c|}{ Haplotype } & \multicolumn{2}{|c|}{ Frequency } & \multirow[b]{2}{*}{ OR $(95 \% \mathrm{Cl})$} & \multirow[b]{2}{*}{$p$} \\
\hline & rs2227631 & rs1799889 & rs11178 & Controls & Patients & & \\
\hline$\overline{\mathrm{Hap} 1^{\mathrm{a}}}$ & $G$ & $5 G$ & $T$ & 0.391 & 0.310 & $1^{*}$ & - \\
\hline Hap2 & A & $4 \mathrm{G}$ & C & 0.305 & 0.398 & $1.63(1.31-2.02)$ & $<0.001$ \\
\hline Hap3 & G & $4 \mathrm{G}$ & C & 0.113 & 0.103 & $1.14(0.83-1.55)$ & 0.425 \\
\hline Hap4 & G & $4 G$ & T & 0.115 & 0.092 & $0.98(0.71-1.34)$ & 0.875 \\
\hline
\end{tabular}

${ }^{a}$ Haplotype G-5G-T (Hap1) was chosen to be the baseline haplotype; *reference category (odds ratio, 1.0)

genetic factors involved in ONFH pathogenesis in a Korean population [24-29]. Some studies have suggested that genetic polymorphisms leading to thrombosis (factor $\mathrm{V}$, prothrombin, MTHFR) may be related to $\mathrm{ONFH}$ $[4,6,16,30,31]$. Intravascular coagulopathy including thrombotic and fibrinolytic abnormalities may play an etiologic role in the disease, and studies have investigated the association between $\mathrm{ONFH}$ and genes involved in the coagulation and fibrinolytic system $[7,11,32]$.

\section{Conclusion}

We found that SNPs of the PAI-1 gene, which is involved in coagulation, were significantly correlated with ONFH. These data suggest that PAI-1, along with already reported candidate genes, may be useful genetic markers to identify high-risk individuals in Korea. The results of this association study suggest that PAI-1 gene polymorphisms may be important genetic factors in ONFH susceptibility in a Korean population. To further substantiate this hypothesis, functional studies of PAI-1 regulation are required. The polymorphisms analyzed in this study may contribute to further studies on the function of PAI-1 and the development of ONFH.

\section{Abbreviations}

ONFH: (osteonecrosis of the femoral head); PAI-1: (plasminogen activator inhibitor-1); SNP: (single nucleotide polymorphism).

\section{Acknowledgements}

This Research was supported by the Program of Kyung Hee University for the Young Researcher in Medical Science (KHU-20081274).

\section{Author details}

${ }^{1}$ Department of Biochemistry and Molecular Biology (BK21 project), Kyung Hee University School of Medicine, Seoul, 130-701, Korea. ${ }^{2}$ MRC for Bioreaction to ROS and Biomedical Science Institute Kyung Hee University School of Medicine, Seoul, 130-701, Korea. ${ }^{3}$ Department of Orthopaedic Surgery, Kyung Hee University Hospital at Gangdong, School of Medicine, Kyung Hee University, Seoul, 134-727, Korea. ${ }^{4}$ Division of AllergyImmunology, Department of Medicine, Feinberg School of Medicine, Northwestern University, Chicago, IL, USA.

\section{Authors' contributions}

KIK and KSY conceived the study, and supervised the study design. HOK, $\mathrm{CHC}$ and YJC were involved in the design of the genotyping assays, sample preparation, and statistical analysis. KIK, HOK and SHC contributed to interpretation of the data. KIK drafted the manuscript together with HOK, CHC, YJC, SHC and KSY. All authors read and approved the final manuscript.

\section{Competing interests}

The authors declare that they have no competing interests.

Received: 22 October 2010 Accepted: 14 July 2011

Published: 14 July 2011

\section{References}

1. Zalavras C, Dailiana Z, Elisaf M, Bairaktari E, Vlachogiannopoulos P, Katsaraki A, Malizos KN: Potential aetiological factors concerning the development of osteonecrosis of the femoral head. Eur J Clin Invest 2000, 30:215-221.

2. Jones LC, Mont MA, Le TB, Petri M, Hungerford DS, Wang P, Glueck CJ: Procoagulants and osteonecrosis. J Rheumatol 2003, 30:783-791.

3. Glueck CJ, Freiberg R, Tracy T, Stroop D, Wang P: Thrombophilia and hypofibrinolysis: pathophysiologies of osteonecrosis. Clin Orthop Relat Res 1997, 334:43-56.

4. Bjorkman A, Svensson PJ, Hillarp A, Burtscher IM, Runow A, Benoni G: Factor $\mathrm{V}$ leiden and prothrombin gene mutation: risk factors for osteonecrosis of the femoral head in adults. Clin Orthop Relat Res 2004, 425:168-172.

5. Glueck CJ, Freiberg RA, Fontaine RN, Tracy T, Wang P: Hypofibrinolysis, thrombophilia, osteonecrosis. Clin Orthop Relat Res 2001, 386:19-33.

6. Celik A, Tekis D, Saglam F, Tunali S, Kabakci N, Ozaksoy D, Manisali M, Ozcan MA, Meral M, Gülay H, Camsari T: Association of corticosteroids and factor V, prothrombin, and MTHFR gene mutations with avascular osteonecrosis in renal allograft recipients. Transplant Proc 2006, 38:512-516.

7. Ferrari $P$, Schroeder $V$, Anderson S, Kocovic L, Vogt B, Schiesser D, Marti HP, Ganz R, Frey FJ, Kohler HP: Association of plasminogen activator inhibitor1 genotype with avascular osteonecrosis in steroid-treated renal allograft recipients. Transplantation 2002, 74:1147-1152.

8. Glueck CJ, Fontaine RN, Gruppo R, Stroop D, Sieve-Smith L, Tracy T, Wang P: The plasminogen activator inhibitor-1 gene, hypofibrinolysis, and osteonecrosis. Clin Orthop Relat Res 1999, 366:133-146.

9. Dawson S, Hamsten A, Wiman B, Henney A, Humphries S: Genetic variation at the plasminogen activator inhibitor-1 locus is associated with altered levels of plasma plasminogen activator inhibitor-1 activity. Arterioscler Thromb 1991, 11:183-190.

10. Eriksson P, Kallin B, van't Hooft FM, Bavenholm P, Hamsten A: Allelespecific increase in basal transcription of the plasminogen-activator inhibitor 1 gene is associated with myocardial infarction. Proc Natl Acad Sci USA 1995, 92:1851-1855.

11. Asano T, Takahashi KA, Fujioka M, Inoue S, Ueshima K, Hirata T, Okamoto M, Satomi Y, Nishino H, Tanaka T, Hirota Y, Kubo T: Relationship between postrenal transplant osteonecrosis of the femoral head and gene polymorphisms related to the coagulation and fibrinolytic systems in Japanese subjects. Transplantation 2004, 77:220-225.

12. Koo KH, Kim R, Kim YS, Ahn IO, Cho SH, Song HR, Park YS, Kim H, Wang GJ: Risk period for developing osteonecrosis of the femoral head in patients on steroid treatment. Clin Rheumatol 2002, 21:299-303.

13. Matsuo K, Hirohata T, Sugioka Y, Ikeda M, Fukuda A: Influence of alcohol intake, cigarette smoking, and occupational status on idiopathic osteonecrosis of the femoralhead. Clin Orthop Relat Res 1988, 234:115-123.

14. Juhan-Vague I, Valadier J, Alessi MC, Aillaud MF, Ansaldi J, Philip-Joet C, Holvoet $P$, Serradimigni A, Collen D: Deficient t-PA release and elevated PA inhibitor levels in patients with spontaneous or recurrent deep venous thrombosis. Thromb Haemost 1987, 57:67-72. 
15. Glueck CJ, Glueck HI, Mieczkowski L, Tracy T, Speirs J, Stroop D: Familial high plasminogen activator inhibitor with hypofibrinolysis, a new pathophysiologic cause of osteonecrosis? Thromb Haemost 1993, 69:460-465.

16. Van Veldhuizen PJ, Neff J, Murphey MD, Bodensteiner D, Skikne BS: Decreased fibrinolytic potential in patients with idiopathic avascular necrosis and transient osteoporosis of the hip. Am J Hematol 1993, 44:243-248.

17. Su S, Chen S, Zhao J, Huang J, Wang X, Chen R, Gu D: Plasminogen activator inhibitor-1 gene: selection of tagging single nucleotide polymorphisms and association with coronary heart disease. Arterioscler Thromb Vasc Biol 2006, 26:948-954.

18. Vaughan DE: PAI-1 and atherothrombosis. J Thromb Haemost 2005, 3:1879-83.

19. Sternlicht MD, Dunning AM, Moore DH, Pharoah PD, Ginzinger DG, Chin K, Gray JW, Waldman FM, Ponder BA, Werb Z: Prognostic value of PAI1 in invasive breast cancer: evidence that tumor-specific factors are more important than genetic variation in regulating PAI1 expression. Cancer Epidemiol Biomarkers Prev 2006, 15:2107-14.

20. Torres-Carrillo NM, Torres-Carrillo N, Vázquez-Del Mercado M, DelgadoRizo V, Oregón-Romero E, Parra-Rojas I, Muñoz-Valle JF: The -844 G/A PAI-1 polymorphism is associated with mRNA expression in rheumatoid arthritis. Rheumatol Int 2008, 28:355-60.

21. Hultman $K$, Tjarnlund-Wolf A, Odeberg J, Eriksson P, Jern C: Allele-specific transcription of the PAl-1 gene in human astrocytes. Thromb Haemost 2010, 104:998-1008.

22. Kerachian MA, Sequin C, Harvey EJ: Glucocorticoids in osteonecrosis of the femoral head: a new understanding of the mechanisms of action. J Steroid Biochem Mol Biol 2009, 114:121-8.

23. Powell C, Chang C, Gershwin ME: Current concepts on the pathogenesis and natural history of steroid-induced osteonecrosis. Clin Rev Allergy Immunol 2010.

24. Hong JM, Kim TH, Chae SC, Koo KH, Lee YJ, Park EK, Choi JY, Ryoo HM, Kim SY: Association study of hypoxia inducible factor 1alpha (HIF1alpha) with osteonecrosis of femoral head in a Korean population. Osteoarthritis Cartilage 2007, 15:688-694.

25. Kim TH, Baek Jl, Hong JM, Choi SJ, Lee HJ, Cho HJ, Park EK, Kim UK, Kim SY: Significant association of SREBP-2 genetic polymorphisms with avascular necrosis in the Korean population. BMC Med Genet 2008, 27(9):94.

26. Koo KH, Lee JS, Lee YJ, Kim KJ, Yoo JJ, Kim HJ: Endothelial nitric oxide synthase gene polymorphisms in patients with nontraumatic femoral head osteonecrosis. J Orthop Res 2006, 24:1722-1728.

27. Kim TH, Hong JM, Lee JY, Oh B, Park EK, Lee CK, Bae SC, Kim SY: Promoter polymorphisms of the vascular endothelial growth factor gene is associated with an osteonecrosis of the femoral head in the Korean population. Osteoarthritis Cartilage 2008, 16:287-291.

28. KIM TH, Hong JM, Oh B, Cho YS, Lee JY, Kim HL, Lee JE, Ha MH, Park EK, Kim SY: Association of polymorphisms in the Interleukin 23 receptor gene with osteonecrosis of femoral head in Korean population. Exp Mol Med 2008, 40:418-426.

29. Kim TH, Hong JM, Shin ES, Kim HJ, Cho YS, Lee JY, Lee SH, Park EK, Kim SY: Polymorphisms in the Annexin gene family and the risk of osteonecrosis of the femoral head in the Korean population. Bone 2009, 45:125-131.

30. Bjorkman A, Burtscher IM, Svensson PJ, Hillarp A, Besjakov J, Benoni G: Factor $V$ Leiden and the prothrombin 20210A gene mutation and osteonecrosis of the knee. Arch Orthop Trauma Surg 2005, 125:51-55.

31. Zalavras CG, Vartholomatos G, Dokou E, Malizos KN: Genetic background of osteonecrosis: associated with thrombophilic mutations? Clin Orthop Relat Res 2004, 422:251-255.

32. Glueck CJ, Freiberg R, Glueck HI, Tracy T, Stroop D, Wang Y: Idiopathic osteonecrosis, hypofibrinolysis, high plasminogen activator inhibitor, high lipoprotein(a), and therapy with Stanozolol. Am J Hematol 1995, 48:213-220.

\section{Pre-publication history}

The pre-publication history for this paper can be accessed here: http://www.biomedcentral.com/1471-2474/12/160/prepub

doi:10.1186/1471-2474-12-160

Cite this article as: Kim et al:: Significant associations of PAl-1 genetic polymorphisms with osteonecrosis of the femoral head. BMC Musculoskeletal Disorders 2011 12:160.

\section{Submit your next manuscript to BioMed Central and take full advantage of:}

- Convenient online submission

- Thorough peer review

- No space constraints or color figure charges

- Immediate publication on acceptance

- Inclusion in PubMed, CAS, Scopus and Google Scholar

- Research which is freely available for redistribution

Submit your manuscript at www.biomedcentral.com/submit
Biomed Central 